\title{
Zoonotic parasites: the One Health challenge
}

\author{
Domenico Otranto $^{1,2} \cdot$ Christina Strube ${ }^{3} \cdot$ Lihua Xiao $^{4}$
}

Published online: 18 June 2021

(c) The Author(s), under exclusive licence to Springer-Verlag GmbH Germany, part of Springer Nature 2021

Over the past 2 years, the COVID-19 pandemic taught the relevance of the integrative one medicine (also known as One Health) to scientists, politicians and laymen, also increasing their awareness of how medical and veterinary sciences are connected (Francis 2021). This concept is paradigmatic in Parasitology with many parasites inhabiting our Earth and perpetuating in domesticated animals, wildlife and... humans. Parasites share the same environments and their lives with those of their hosts. They spread globally, without boundaries, across the continents. Their biological life cycles have been elegantly shaped by time to fit those of their hosts during evolution, making Parasitology a science as yet unwritten. Therefore, Parasitology is a clear example embodying the holistic approach of medical and veterinary medicine. One of the major contributions to the definition of One Health was by Calvin W. Schwabe (1927-2006), a veterinary epidemiologist who worked on many aspects of zoonoses including their control, tropical health, public health practice and the philosophy of science.

In this context, this special issue on "Zoonotic parasites: the One Health challenge" has been conceived in order to cover the broader range of zoonotic parasites worldwide, providing an update on those of both wildlife and domestic animals. In wildlife, the parasites of Didelphis spp. opossums have been investigated in the Americas, highlighting the risks of pathogen transmission due to the direct and indirect interactions between humans and domestic animals

Domenico Otranto

domenico.otranto@uniba.it

1 Department of Veterinary Medicine, University of Bari, Bari, Italy

2 Department of Pathobiology, Faculty of Veterinary Science, Bu-Ali Sina University, Hamedan, Iran

3 Institute for Parasitology, Centre for Infection Medicine, University of Veterinary Medicine Hannover, Hannover, Germany

4 Center for Emerging and Zoonotic Diseases, College of Veterinary Medicine, South China Agricultural University, Guangzhou, China and Didelphis (Bezerra-Santos et al. 2021a). The same risks for pathogen transmission have been shown for many carnivores (e.g., red foxes, stone martens and raccoon dogs) from periurban areas in northern Germany, demonstrating the potential impact of human encroachment on destruction of forests and local environments (Waindok et al. 2021). An important focus is zoonotic vector-borne diseases (VBDs) in the less known areas of Iran and Pakistan, where up to $47 \%$ of dogs yielded positive results for VBDs, some of which are of zoonotic concern (Iatta et al. 2021). Similarly, Leishmania tropica has been diagnosed in dogs and humans in Saudi Arabia, and Leishmania major in humans (Alanazi et al. 2021), further suggesting the role of a variety of animal species as reservoirs of zoonotic Leishmania spp. The VBD section is nicely complemented by an informative review article on diagnostic methods for tick-borne zoonoses caused by protozoan, bacterial and viral pathogens worldwide (Springer et al. 2021). Dirofilariosis caused by Dirofilaria immitis is discussed in cats (a rather unsuitable host!) in newly endemic areas of southern Italy (Panarese et al. 2021), where human infections are on the rise. Animals may represent a useful model for studies of human filariae spp. (e.g., Onchocerca volvulus, Wuchereria bancrofti and Brugia spp., Loa loa and Mansonella spp.) and this is reviewed in a comprehensive article focused on recent advances with Litomosoides sigmodontis and Acanthocheilonema viteae in a filarial mouse model (Risch et al. 2021).

Undoubtedly, foodborne parasites play a prominent role in zoonotic transmission, which is discussed with a focus on Taenia spp. and Trichinella spp. in areas, such as the Far East countries, where scientific information is often scant due to lack of published information (Liu et al. 2021). The same applies to many geographical areas of the Arab World where such studies are rare, primarily due to religious proscriptions (Abuseir 2021). In addition, the major global concern raised by waterborne diseases which result in high morbidity and mortality, and massive economic costs, is recognised. Therefore, the transmission of waterborne pathogens (e.g., by Cryptosporidium spp.) is reviewed for small ruminants (Guo et al. 2021). These reviews are well supplemented by 
an assessment of the analysis of wastewater to monitor the emergence and spread of infectious diseases at a population level (Zahedi et al. 2021). Wastewater-based epidemiology has also been focused in light of the current COVID-19 pandemic. For some parasites, which are considered to typically affect humans, the role of animals in the maintenance of their life cycles is discussed. This is the case of Tunga penetrans, Tunga trimamillata and Tunga hexalobulata (i.e., sand fleas), that have been mainly studied in humans, but less so in dogs and other animal species in spite of their major public health and animal health significance (Mutebi et al. 2021). Overall, national public health surveillance services should undertake systematic surveys to monitor not only zoonotic parasites but also human activities (e.g., illegal wildlife trade), which could represent a risk factor for the introduction of these pathogens into previously non-endemic areas (Bezerra-Santos et al. 2021b). Again, medical professionals from non-endemic areas should be informed on the diagnosis and management of zoonotic parasites in order to control and prevent the spreading of parasitic diseases from animals to humans and...vice versa.

\section{References}

Abuseir S (2021) Meat-borne parasites in the Arab world: a review in a One Health perspective. Parasitol Res. https://doi.org/10.1007/ s00436-021-07149-0

Alanazi AD, Alouffi AS, Alyousif MS, Rahi AA, Ali MA, Abdullah HHAM, Brayner FA, Mendoza-Roldan JA, Bezerra-Santos MA, Otranto D (2021) Molecular characterization of Leishmania species from stray dogs and human patients in Saudi Arabia. Parasitol Res. https://doi.org/10.1007/s00436-021-07166-z

Bezerra-Santos MA, Ramos RAN, Campos AK, Dantas-Torres F, Otranto D (2021a) Didelphis spp. opossums and their parasites in the Americas: a One Health perspective. Parasitol Res. https:// doi.org/10.1007/s00436-021-07072-4
Bezerra-Santos MA, Mendoza-Roldan JA, Thompson RCA, DantasTorres F, Otranto D (2021b) Illegal wildlife trade: a gateway to zoonotic infectious diseases. Trends Parasitol 37(3):181-184

Francis MJ (2021) How has Covid-19 changed our views of the One Health agenda? Vet Rec 188:361

Guo Y, Li N, Ryan U, Feng Y, Xiao L (2021) Small ruminants and zoonotic cryptosporidiosis. Parasitol Res. https://doi.org/10.1007/ s00436-021-07116-9

Iatta R, Sazmand A, Nguyen VL, Nemati F, Ayaz MM, Bahiraei Z, Zafari S, Giannico A, Greco G, Dantas-Torres F, Otranto D (2021) Vector-borne pathogens in dogs of different regions of Iran and Pakistan. Parasitol Res. https://doi.org/10.1007/ s00436-020-06992-x

Liu Y, Dong Z, Pang J, Liu M, Jin X (2021) Prevalence of meat-transmitted Taenia and Trichinella parasites in the Far East countries. Parasitol Res. https://doi.org/10.1007/s00436-021-07124-9

Mutebi F, Krücken J, Feldmeier H, von Samsom-Himmelstjerna G (2021) Clinical implications and treatment options of tungiasis in domestic animals. Parasitol Res. https://doi.org/10.1007/ s00436-021-0712

Panarese R, Iatta R, Lia RP, Passantino G, Ciccarelli S, Gernone F, Zatelli A, Otranto D (2021) Dirofilarioses in two cats in southern Italy. Parasitol Res. https://doi.org/10.1007/s00436-021-07127-6

Risch F, Ritter M, Hoerauf A, Hübner MP (2021) Human filariasis-contributions of the Litomosoides sigmodontis and Acanthocheilonema viteae animal model. Parasitol Res. https://doi. org/10.1007/s00436-020-07026-2

Springer A, Glass A, Probst J, Strube C (2021) Tick-borne zoonoses and commonly used diagnostic methods in human and veterinary medicine. Parasitol Res. https://doi.org/10.1007/ s00436-020-07033-3

Waindok P, Raue K, Grilo ML, Siebert U, Strube C (2021) Predators in northern Germany are reservoirs for parasites of One Health concern. Parasitol Res. https://doi.org/10.1007/s00436-021-07073-3

Zahedi A, Monis P, Deere D, Ryan U (2021) Wastewater-based epidemiology-surveillance and early detection of waterborne pathogens with a focus on SARS-CoV-2, Cryptosporidium and Giardia. Parasitol Res. https://doi.org/10.1007/s00436-020-07023-5

Publisher's Note Springer Nature remains neutral with regard to jurisdictional claims in published maps and institutional affiliations. 